\title{
MODO DE PRODUÇÃO E EDUCAÇÃO: APONTAMENTOS SOBRE A EDUCAÇÃO NA REPRODUÇÃO CAPITALISTA E NA TRANSIÇÃO AO SOCIALISMO
}

\author{
MODO DE PRODUCCIÓN Y EDUCACIÓN: APUNTES SOBRE LA EDUCACIÓN EN LA \\ REPRODUCCIÓN CAPITALISTA Y EN LA TRANSICIÓN AL SOCIALISMO
}

\section{MODE OF PRODUCTION AND EDUCATION: CONSIDERATIONS ABOUT EDUCATION IN THE CAPITALIST REPRODUCTION AND IN THE TRANSITION TO THE SOCIALISM}

\author{
Patrícia Vieira Trópia ${ }^{1}$
}

\begin{abstract}
Resumo: Elabora-se neste texto uma interpretação da relação entre modo de produção e educação, a partir das contribuições da visão althusseriana. As contribuições desta abordagem possibilitam a crítica à visão economicista e reducionista acerca do tipo de articulação existente entre a base/estrutura econômica e a superestrutura política e ideológica e suas implicações para a educação. Deste ponto de vista, a escola, a educação escolar, não só pode como é um local de contradição. Entretanto, qualquer transformação interna à escola no sentido de torná-la, de fato, uma escola a serviço das classes trabalhadoras exigiria o rompimento com o compromisso orgânico do aparelho educacional. Dos enfoques em contraponto: economicismo e estruturalismo, decorre a indagação: "embora algumas críticas às armadilhas das leituras não-economicistas sejam pertinentes, a rejecção das análises desenvolvidas pela "sociológica crítica da educação" no campo educacional não pode nos colocar em outras tantas e mais perversas armadilhas, como as do idealismo e do reformismo?".
\end{abstract}

Palavras-chave: Modo de produção. Educação; Economicismo; Estruturalismo.

Resumen: Se elabora en este texto una interpretación de la relación modo de producción y educación, a partir de las contribuciones de la visión althusseriana. Las contribuciones de esta proposición posibilitan la crítica a la visión economicista y reduccionista acerca del tipo de articulación existente entre la base/estructura económica y la superestructura política e ideológica y sus implicaciones para la educación. De este punto de vista, la escuela, la educación escolar, no sólo puede como es un local de contradicción. Entretanto, cualquier transformación interna a la escuela en el sentido de tornarla, de hecho, una escuela a servicio de las clases trabajadoras exigiría el rompimiento con el compromiso orgánico del aparato educacional. De los enfoques en oposición: economicismo y estructuralismo transcurre la indagación: "aunque algunas críticas a las trampas de las lecturas no economicistas sean pertinentes, el rechazo de los análisis desarrollados por la "sociológica crítica de la educación" en el campo educacional no puede colocarnos en otras tantas y más perversas trampas, como las del idealismo y del reformismo?".

Palabras-clave: Modo de producción. Educación; Economicismo; Estructuralismo.

\begin{abstract}
This text works about the relation between mode of production and education, from the contributions of the althusseriana view. The contributions of this approach allow the overcoming review to the economicist and reductionist view about the kind of articulation between the base/economic structure and the political and ideological superstructure and its implications for education. From this point of view, the school, the school education, is really a place of contradiction. However, any internal transformation to the school to make it, in fact, a school to serve the working classes would demand a breakup with the organic commitment of the educational unit. But from different approaches, economism and structuralism, come the question: "although some criticisms to the traps of the non-economist reviews are pertinent, cannot the rejection of the tests developed by the 'sociological criticism of the education' in the educational field put us in so many others and more devilish traps, such as those from idealism and reformism?".
\end{abstract}

Key words: Mode of production; Education; Economicism; Structuralism.

Primeira Parte - O conceito de modo de produção 
O mais conhecido e, não menos, polêmico texto de Marx sobre o conceito de modo de produção encontra-se no Prefácio ao seu livro Para a Crítica da Economia Política, de 1859. Neste texto estão expressos alguns dos fundamentos do materialismo histórico - a ciência formulada e desenvolvida por Marx e Engels. Na passagem mais famosa do Prefácio de 1859 estão contidas expressões materialistas, tais como totalidade social, determinação, estrutura e superestrutura, correspondência, condicionalidade, desenvolvimento das forças produtivas, contradição, revolução social, consciência, conflito e finalmente o conceito mais operacional do materialismo histórico: o de modo de produção (WOOD, 2003).

Ao tratar o tema "Modo de Produção e Educação", não é senão a partir do emblemático texto do Prefácio que inicio minha análise. Embora extensa, a citação aqui se impõe:

[...] na produção social da sua vida os homens entram em determinadas relações, necessárias, independentes da sua vontade, relações de produção que correspondem a uma determinada etapa de desenvolvimento das suas forças produtivas materiais. A totalidade destas relações de produção forma a estrutura econômica da sociedade, a base real sobre a qual se ergue uma superstrutura jurídica e política, e à qual correspondem determinadas formas da consciência social. O modo de produção da vida material é que condiciona o processo da vida social, política e espiritual. Não é a consciência dos homens que determina o seu ser, mas, inversamente, o seu ser social que determina a sua consciência. Numa certa etapa do seu desenvolvimento, as forças produtivas materiais da sociedade entram em contradição com as relações de produção existentes ou, o que é apenas uma expressão jurídica delas, com as relações de propriedade no seio das quais se tinham até aí movido. De formas de desenvolvimento das forças produtivas, estas relações transformam-se em grilhões das mesmas. Ocorre então uma época de revolução social. Com a transformação do fundamento econômico revoluciona-se, mais devagar ou mais depressa, toda a imensa superstrutura. $\mathrm{Na}$ consideração de tais revolucionamentos tem de se distinguir sempre entre o revolucionamento material nas condições econômicas da produção, o qual é constatável rigorosamente como nas ciências naturais, e as formas jurídicas, políticas, religiosas, artísticas ou filosóficas, em suma, ideológicas, em que os homens ganham consciência deste conflito e o resolvem. Do mesmo modo que não se julga o que um indivíduo é pelo que ele imagina de si próprio, tão-pouco se pode julgar uma tal época de revolucionamento a partir da sua consciência, mas se tem, isso sim, de explicar esta consciência a partir das contradições da vida material, do conflito existente entre forças produtivas e relações de produção sociais. Uma formação social nunca decai antes de estarem desenvolvidas todas as forças produtivas para as quais é suficientemente ampla, e nunca surgem relações de produção novas e superiores antes de as condições materiais de existência das mesmas terem sido chocadas no seio da própria sociedade velha (MARX, 1982).

Este texto lança algumas pistas para compreendermos a concepção marxiana sobre a "produção da vida", ou seja como é que a vida se produz e se reproduz. Inicialmente, Marx afirma que, na produção social da sua vida, os homens entram em determinadas relações, independentes de sua vontade, relações de produção que correspondem a uma determinada etapa do desenvolvimento de suas forças produtivas materiais. De partida, duas interpretações devem ser destacadas. 1) A produção da vida não é, pois, aleatória, não é fortuita e nem arbitrária; ao contrário ela é condicionada por relações de produção que, por sua vez, correspondem a determinados níveis de desenvolvimento das forças produtivas materiais (o trabalho, a ciência, a organização da produção, os meios de produção); 2) as relações de produção constituem a estrutura da sociedade, a base sobre a qual se erguem e se sustentam as estruturas jurídicopolíticas que a elas correspondem. Estas duas proposições delineiam o conceito marxiano de modo de produção. O modo de produção condiciona o processo de vida social, política, cultural etc. O modo de 
produção da sociedade, ou o que Marx neste mesmo trecho chamará de "estrutura econômica da sociedade", condiciona o processo social, político e ideológico em geral. Neste sentido, a política, o Estado, a educação, a cultura, as idéias, as ideologias (enfim, o conjunto da superestrutura) não existem por si mesmas, não são autônomas, não são independentes. Eles estão condicionados fortemente - isto é, determinadas - pela estrutura econômica da sociedade. O trecho até aqui interpretado nos permite afirmar, de imediato, que a educação não é uma dimensão natural, mas histórica e - como parte da superestrutura - é expressão da base material da sociedade. Mas prossigamos.

Além disso, o Prefácio também lança algumas pistas para compreendermos a concepção marxiana sobre a "transformação da vida material", ou seja como é que a vida social se transforma. Ali Marx nos diz que, em certa etapa de seu desenvolvimento, as forças produtivas materiais da sociedade entram em contradição com as relações de produção existentes ou com as relações de propriedade. As relações de produção, que impulsionavam até então as forças produtivas, obstaculizam-nas, originando assim um período de revolução social.

Desta feita, o trecho por nós escolhido para fundamentar a concepção marxiana de modo de produção trata do que faz a vida social se reproduzir e do que faz a vida social se transformar, ou seja trata da reprodução e da transição. Desde já, uma questão deve ser formulada: que papel, que funções e que dimensões assumiriam a educação escolar na reprodução capitalista e na transformação social, vale dizer na transição do capitalismo ao socialismo? Guardemos esta questão pois ela nos guiará mais à frente. Por ora, tratemos de refletir sobre alguns dos desdobramentos e interpretações acerca do conceito de modo de produção esboçado no Prefácio de 1859.

Este trecho do Prefácio e o conhecido ensaio de Stalin Materialismo bistórico e materialismo dialético suscitaram, no interior da tradição marxista, sobretudo no período da II Internacional, uma leitura economicista e reducionista acerca do tipo de articulação existente entre a base/estrutura econômica e a superestrutura política e ideológica (SAES, 1994).

De forma sintética e de acordo com esta leitura, o elemento causal da produção da vida social seria a estrutura econômica, enquanto o elemento dinâmico da revolução social seria o desenvolvimento progressivo, continuado, de tipo evolucionista - das forças produtivas. A estrutura econômica moveria, assim, não apenas a reprodução no longo prazo, mas também a transformação social. O essencial da leitura economicista é que o modo de produção diz respeito apenas e tão somente às relações de produção e forças produtivas e que, em conseqüência disso, a superestrutura aparece como mero reflexo externo da infra-estrutura. A política, o Estado, a cultura, a ideologia e, também nosso objeto central, a educação se comportariam de forma epifenomênica, mais ou menos "como o efeito dominó", face ao processo e ao desenvolvimento econômico. A transformação da base econômica determinaria unilateralmente a transformação da superestrutura.

Sobretudo a partir da década de 1960, em reação às leituras economicistas e reducionistas suscitadas pelo Prefácio, são desenvolvidas análises não-economicistas (TURCHETTO, 2005) - também designadas por marxismo político por Ellen Wood (2003) - sobre a articulação entre as estruturas do modo de produção. A mais importante destas reações coube aos althusserianos, embora Antonio Gramsci 
tenha sido um dos pioneiros na crítica ao economicismo/determinismo, ao afirmar a centralidade da questão política na análise marxista e o caráter mais complexo da dominação e do poder burgueses.

$\mathrm{Na}$ análise de um conhecido estudioso do pensamento de Althusser, Décio Saes (1994), a análise desenvolvida pelos althusserianos tinha duas intenções fundamentais: criticar a concepção especulativa e idealista sobre a ação humana - presente nas chamadas obras da juventude - e a concepção sobre a natureza economicista do todo social, presente no Prefácio. Com o intuito de criticar a relação de exterioridade entre a estrutura econômica e a política, por exemplo, os althusserianos propuseram uma ampliação do conceito de modo de produção e outra interpretação sobre a articulação entre base e superestrutura. O conceito de modo de produção designava não apenas a infraestrutura - relações de produção e forças produtivas - mas também a superestrutura - relações jurídico-políticas e ideológicas. Por sua vez, a relação entre as instâncias não seria de simples determinação, mas de dominância e de implicação recíproca.

Neste outro esquema conceitual, as relações de produção capitalistas não mais determinam as relações jurídico-políticas ou ideológicas, mas as supõem. A superestrutura condiciona a estrutura, vale dizer "cada instância se configura como condição necessária à reprodução das demais instâncias" (CODATO, 2007). Em síntese, as análises dos althusserianos acerca do materialismo histórico procuraram ressaltar que as estruturas da sociedade são interdependentes, ou seja que umas dependem das outras, e que a reprodução social, isto é o funcionamento da sociedade e sua continuidade no tempo largo, exige sempre a intervenção recíproca entre as estruturas econômica, política e ideológica.

Foram também os althusserianos os responsáveis pela crítica à tese, presente no Prefácio, do primado das forças produtivas na revolução social, isto é na transição. Coube particularmente a Balibar, o esforço de reflexão sobre o processo de transição de um modo de produção a outro, no interior daquela corrente. $\mathrm{Na}$ fase de transição de um modo de produção a outro, as seguintes características invariantes poderiam ser observadas: não correspondência entre relações de produção e forças produtivas e não correspondência entre as estruturas econômica, política e ideológica. Ou seja, não existiria no período de transição nem intervenção, nem correspondência recíproca. Qual seria então a articulação, proposta por Balibar, entre as forças produtivas e as relações de produção? Esquematicamente, Balibar inverte os termos propostos no Prefácio, ao afirmar que as relações de produção precedem, nas fases de transição, as forças produtivas e que a instância jurídica anteciparia as mudanças nas instâncias econômica e ideológica - indicando, assim, um papel preponderante da denominada superestrutura jurídico política nas fases de transição. Esclareça-se, desde logo, que as formulações de Balibar e demais althusserianos suscitaram críticas e polêmicas. $\mathrm{Na}$ medida em que afirmava a procedência das relações de produção sob as forças produtivas, o esquema althusseriano seria acusado de sucumbir com a luta de classes e as contradições geradas, como apontava Marx, pelo desenvolvimento das forças produtivas.

Ao retomar os textos althusserianos, Saes, no ensaio "Marxismo e história", publicado em 1994 pela revista Crítica Marxista, apresenta-nos uma reinterpretação das análises de Balibar sobre a problemática da transição. Para Saes, o esboço de uma teria geral da transição, desenhado por Balibar, conteria, além daquela caracterização acima, o pressuposto de que a reprodução da estrutura econômica de 
qualquer modo de produção apresenta uma dimensão cumulativa: o desenvolvimento das forças produtivas. Estas forças produtivas passariam por processos de desenvolvimento não meramente reprodutores, nem evolutivos e progressivos, mas contraditórios e potenciais. Nesta reinterpretação, a causa das transformações estaria, assim, no desenvolvimento das forças produtivas, registrado, contudo, não apenas no período de revolução social mas, na própria vigência de relações de produção anteriores. Ou seja, o desenvolvimento "em espiral" das forças produtivas - por exemplo, a socialização crescente do processo produtivo no capitalismo - criaria as condições para a transformação de contradições, no sentido fraco do termo, em contradições fundamentais, ou seja a transformação dos conflitos sociais e antagonismos políticos propriamente ditos - em duas palavras, na luta de classes.

Embora o marxismo político tenha sofrido inúmeras críticas por seu caráter "mecanicista", por engessar a história, ou pelo abandono do campo das realidades econômicas, segundo Wood (2003), ele teria o mérito de tomar o modo de produção como um fenômeno social, tomar as relações de produção em seu aspecto político e ideológico, como relações de dominação, como direitos de propriedade, com o poder de organizar e governar a produção e a apropriação. O marxismo político tem o mérito de analisar o tipo de relação entre base e superestrutura não como estruturas separadas e estanques, mas articuladas e interdependentes. Segundo Turchetto (2005), a crítica ao economicismo permite, entre outros avanços teóricos, a ampliação do conceito de modo de produção, a problematização das formações sociais e da coexistência de diferentes modos de produção, a superação da tese do primado das forças produtivas como lei universal da história e, com especial ênfase para os objetivos de nossa exposição, o rompimento com aquela parte do marxismo que permanecia atrelada à ideologia burguesa da "neutralidade" das forças produtivas e, neste sentido, da ciência, da técnica, da organização da produção face à estrutura das relações sociais.

Passemos agora à segunda parte de nossa exposição. Que repercussões teriam para a análise da educação estas concepções apresentadas até aqui acerca do modo de produção? Ou dito de outra forma, quais as repercussões das abordagens economicista e não-economicista para a análise da educação?

\section{Segunda parte - Educação e reprodução social}

A leitura economicista produz conseqüências para a análise do modo de produção em geral e da superestrutura, em particular. Procuremos, pois, destacar algumas conseqüências que julgamos importantes para a análise da educação, enquanto parte da superestrutura.

Nesta análise, a educação teria uma existência epifenomênica, uma função social econômica tão somente. A educação e a escola não teriam qualquer autonomia; teriam, no modo de produção capitalista, uma função positiva para o capital e uma função invariavelmente negativa para os trabalhadores. Não haveria - nas instituições educativas - espaço de conflito potencial, nem de contradição. Pode-se derivar, que a organização do ensino, os conteúdos educativos, a função dos docentes ou a função social do conhecimento transmitido nas instituições educativas teriam sempre um sentido unívoco, voltado para a dominação econômica de classes. Não haveria espaço de crítica, de contestação, nem - para usarmos uma 
expressão tão cara a Gramsci - de construção da contra-hegemonia, de negação da ordem estabelecida no plano da superestrutura. $\mathrm{Na}$ medida em que o economicismo concebe o desenvolvimento das forças produtivas de forma progressiva, evolutiva e ascendente - portanto, sem possibilidade de regressão e recuo - a ciência, a organização da produção, a própria educação teriam sua evolução e sua transformação garantidas a priori. Neste sentido, a educação cumpriria um papel secundário, na reprodução e na transformação social, inerte e, tão somente, condicionado pelas relações de produção dominantes. O espaço de luta principal dar-se-ia no plano da produção, onde as contradições potencialmente se desenvolvem.

No campo educacional, um exemplo desta leitura economicista é o conhecido manual de história da educação de Ponce (1990). Tal como foi observado por Gilberto Alves (2001), as análises de Aníbal Ponce, embora surpreendam pelo caráter inédito no campo da historiografia, refletem em certa medida esta concepção vulgar e economista do materialismo histórico. A educação, na obra de Ponce, é analisada fundamentalmente a partir dos determinantes econômicos das sociedades primitivas, escravista, feudal e capitalista. A educação tem a função e o papel de garantir a dominação econômica dos proprietários dos meios de produção em cada período histórico sobre os dominados. Embora mencione a luta de escravos, as revoltas de servos e camponeses, a luta operária e socialista, a luta das classes no interior da superestrutura burguesa, em especial dos aparelhos escolares, é desconsiderada.

Um outro desdobramento ou conseqüência da leitura economicista é uma certa crença na neutralidade das forças produtivas e, consequentemente, do progresso técnico, da ciência, da educação. Embora Marx tenha se dedicado no Livro I de O Capital à análise das duas formas de mais-valia, a absoluta e a relativa, algumas análises economicistas tendem a simplificar a mais-valia relativa. Marx demonstrou que no sistema capitalista é fundamental a relação entre o trabalho necessário para a reprodução da força de trabalho operária e o tempo de trabalho extra fornecido pelo trabalhador. Embora o aumento da produtividade do trabalho - gerada pelo progresso técnico, pelo avanço da ciência, pelo desenvolvimento educacional, pela educação profissional - possa reduzir o tempo de trabalho socialmente necessário para a reprodução da força de trabalho, isto não significa diminuição automática da jornada de trabalho, nem liberação do trabalhador, nem redução de mais-valia. Significa, antes, que o capitalista impelido pela concorrência e também pela luta de classes - procurou intensificar, sob novas formas, a exploração da força de trabalho. Não há simetria mecânica, portanto, entre progresso técnico e revolução social.

Vejamos agora que repercussões a perspectiva não-economicista trouxe para a compreensão do papel da educação na reprodução social.

A ampliação do conceito de modo de produção, a reformulação do conceito de contradição, a definição da correspondência recíproca como o tipo de articulação entre as instâncias, enfim a nova problemática althusseriana permite-nos compreender de forma mais eficaz o papel da educação na reprodução do modo de produção. A partir da contribuição do marxismo estruturalista, a superestrutura o Estado, os aparelhos ideológicos - passou a ser concebida não como uma instância derivada das relações de produção, mas condição de seu funcionamento, em duas palavras, condição de sua reprodução. Nesta 
direção, o filósofo francês Louis Althusser, junto com Baudelot, Establet, Bowles, Gintis, Bourdieu e Passeron, desenvolveu um conjunto de análises da educação e da escola capitalista, criando uma nova tradição na sociologia da educação: "sociologia da educação crítica" (SILVA, 1992), ou "teorias críticoreprodutivistas da educação" (SAVIANI, 1987). Segundo Althusser o Estado é composto por aparelhos ideológicos e repressivos cuja função é garantir as condições gerais de reprodução do modo de produção capitalista. Ele é um instrumento de reprodução das relações de produção, portanto da reprodução das condições de exploração. O aparelho ideológico escolar é composto por várias instituições, organizações e práticas, sendo a escola uma de suas instâncias. Mas de que forma o aparelho escolar contribuiria para - ao condicionar as relações de produção capitalistas - a reprodução do modo de produção capitalista?

Coube a Baudelot e Establet (1973), no início da década de 1970, evidenciar o papel estrutural da escola na reprodução do modo de produção capitalista. Com o objetivo de criticar o mito da escola única, a suposta neutralidade dos processos de escolarização e dos conteúdos e práticas didáticas, estes autores demonstraram que a escola capitalista reproduz a divisão de classe no seu próprio interior, distribuindo seus alunos em dois sistemas desiguais, ainda que sob a aparência da escola única. A escola capitalista, na medida em igualiza os desiguais, reproduz o individualismo burguês - aspecto fundamental para "cimentar" as relações de produção e a exploração de classe. Esta redistribuição dos indivíduos em classes sociais (já que a divisão de classes precede a escola), longe de ser acidental, é intrínseca à organização da escola, é estrutural e absolutamente necessária para a reprodução da divisão do trabalho. Como destacou Establet (1973), a separação dos alunos em duas redes não seria o resultado da escolarização, mas sim o meio e o princípio de seu funcionamento.

Por sua vez, a escola capitalista também assume a função política de inculcar a ideologia burguesa e difundi-la, como verdade, como ciência, no interior da escola. O processo de difusão ideológica não ocorre apenas por meio da transmissão de idéias, mas também de práticas pedagógicas materiais: processos avaliativos, processos de emulação (premiação e punição).

Mas, na análise de Establet (1973) a educação escolar não apenas mistifica e inculca a ideologia dominante, ela também transmite conteúdos e conhecimentos objetivos, muito embora o faça sempre de forma a-histórica, neutra, evolutiva, progressiva, alienada das lutas históricas pelo domínio científico e tecnológico. No fundamental, o aparelho escolar também tem uma função diretamente vinculada à divisão social do trabalho. As relações de produção capitalistas são marcadas por uma dupla separação: a separação entre produtor direto dos meios de produção e a separação entre produtor direto das condições de trabalho, vale dizer a desapropriação por parte do produtor direto (o trabalhador) do controle do processo de trabalho - aquilo que Marx denominou "subsunção real" e "subsunção formal" do trabalho ao capital. A não propriedade dos meios de produção e a divisão técnica do trabalho por parte do produtor direto constituem, portanto, a dupla condição de existência do capital. Cabe ao aparelho escolar a formação técnica e ideológica da força de trabalho, especializando os trabalhadores segundo o padrão produtivo, impedindo que eles obtenham os conhecimentos científicos necessários ao controle técnico/cognitivo do processo produtivo. Cabe, assim, ao aparelho escolar formar distintamente o trabalho manual e o trabalho não manual, ao mesmo tempo em que deve ocultar tal distinção. Esta 
ocultação, é preciso repetir, não ocorre apenas no terreno das idéias e dos conteúdos, mas é estrutural, ou seja, a própria forma como a escola e o ensino estão organizados (escola única, êxito segundo as capacidades, distribuição por critérios meritocráticos) oculta cotidianamente a natureza de classe da escola.

Este processo de inculcação ideológica não ocorre, notadamente, sem contradições e lutas. Embora a contradição principal da sociedade capitalista preceda a escola, como aparelho ideológico a escola é um instrumento, e local, desta luta ideológica de classes e, portanto, de disputa. Segundo Establet, justamente por ser um local de disputa ideológica, a escola não pode abrir mão de práticas repressivas, disciplinares e coercitivas. "Para realizar a inculcação de sua ideologia sob suas diferentes formas, a classe burguesa deve lutar contra as resistências, contra um inimigo real (...) eis porque o processo de inculcação tem como condição o recalcamento, a sujeição e o disfarce da ideologia proletária" (ESTABLET, 1973, p. 100).

Passemos, agora, para a última parte de nossa exposição e apontemos que repercussões algumas leituras não-economicistas trazem para a compreensão do papel da educação na transição socialista.

\section{Terceira parte - Educação e transformação socialista}

Certamente, uma das contribuições das leituras não-economicistas é pensar o aparelho escolar e a educação formal, não formal e informal como campos ou instrumentos de luta, como espaços de disputa. Mas, embora, seja este um avanço importante, existem diferentes posições teóricas e políticas sobre a natureza dos conflitos e da luta de classes, no interior do aparelho escolar.

Não obstante, antes mesmo deste tema ganhar importância nas obras de Gramsci, Bourdieu, Establet e Baudelot, ou ainda para a corrente alhtusseriana, as experiências práticas do movimento operário e socialista e as questões levantadas por seus intelectuais e dirigentes já apontavam a problemática da natureza dos conflitos no interior da escola. Bastante revelador, neste sentido, é o trabalho de Daniel Lindenberg (1972), intitulado L'internationale communiste et l'école de classe, em que são apresentados textos de partidos membros e de instâncias ligadas à III Internacional Comunista. Os textos tratam de temas, tais como revolução ideológica, educação de classe, mito reformista da escola única, conteúdos ideológicos, mito reformista da escola nacional, programas escolares comunistas e, notadamente, da natureza das lutas de classe no interior da escola. De forma sintética, Lindenberg (1972) ressalta que, enquanto na II Internacional predominou uma concepção neutra da escola e a crença no seu potencial igualizador, a III Internacional concentrou uma série de debates sobre a natureza de classe da escola, debates que continham uma crítica radical da escola capitalista, de seu caráter mistificador por um lado, e, por outro, indicavam a necessidade de transformar a linguagem humanista e teoricista presente na escola em uma formação política e científica prática.

Mais conhecidas são, todavia, as análises de Gramsci sobre o papel da luta ideológica nos interior dos chamados "aparelhos privados de hegemonia". A questão central da reflexão de Gramsci era explicar como se exerce o poder político, como se dá a dominação social na ordem capitalista ocidental. Ao discutir esta questão, enfatizou e esboçou de forma original o tema da hegemonia e da direção 
intelectual e moral como elementos decisivos para explicar como se dá a dominação social e política no ocidente capitalista. Gramsci foi assim levado a discutir qual seria a estratégia mais adequada para a Revolução no ocidente: luta política aberta contra o poder de Estado e/ou luta pela hegemonia cultural e ideológica? Nos seus termos "guerra de movimento" ou "guerra de posições"? A ênfase dada por Gramsci à guerra de posições ou luta pela hegemonia o conduziu a redimensionar o papel da cultura e a pensar a escola como um espaço de luta contra-hegemônica - o que significava que, para Gramsci, o aparelho escolar (a escola unitária, por exemplo) seria, sim, um lugar de contradição. Crítico da dualidade da escola burguesa, a escola das massas populares - escola desinteressada, escola humanista - deveria, para Gramsci, se constituir como local de organização cultural, de "consciência unitária".

Como aparelho privado de hegemonia a escola tem o objetivo de organizar o consenso das massas em torno de determinadas concepções de mundo e ganhar a adesão destas massas às idéias e à orientação dos grupos dominantes. Ou seja, os aparelhos de hegemonia têm o objetivo não apenas de difundir a ideologia e as orientações dominantes, mas tornar estas ideologias aceitas por outros grupos sociais. Os aparelhos de hegemonia, inicialmente tratados como locais de universalização do particular, tornam-se ao longo da obra gramsciana locais de luta ideológica de classes.

Mas, que tipo de contradição a escola condensa e pode fazer eclodir? Contradição principal, contradição secundária? Para enfrentar esta questão é preciso realizar um esforço teórico e de pesquisa que não nos propusemos aqui. Por isso, minhas conclusões são mais ensaístas do que demonstrativas.

\section{Breve conclusão}

Uma parte dos marxistas que pesquisam a educação - especialmente aqueles influenciados pelo humanismo teórico tão difundido por Paulo Freire - crê no potencial revolucionário da educação em geral e da educação escolar nos marcos do capitalismo. Também hoje, estaria subjacente às análises sobre o papel da escola um discurso reformista no campo educativo, segundo o qual a luta por reformas na escola seria suficiente para transformar - sem uma revolução social propriamente dita - a sociedade rumo ao socialismo (PORTUGAL, 2007). Segundo Portugal, valendo-se das análises de Lênin e Iskra,

[...] as transformações necessárias para o desenvolvimento do socialismo só poderiam ser realizadas mediante a tomada do poder político e a direção político-ideológica da classe operária, organizada em partido revolucionário (autofinanciado, com imprensa e sedes autônomas, com acúmulo científico e organizativo suficientes para o amadurecimento histórico necessário para as tarefas da revolução). (PORTUGAL, 2007, p. 17)

É preciso assinalar que as concepções inspiradas no marxismo filosófico, nas obras de juventude de Marx e Engels, ou na problemática da II Internacional - como sabemos dominada pela socialdemocracia - acabam por compreender as instituições de ensino, sobretudo as escolas públicas, como instrumentos privilegiados de luta contra-hegemônica. Mas, recoloquemos, que tipo de contradição a escola condensa e pode fazer eclodir?

A escola, não só pode como, é um local de contradição. O pensamento crítico e o pensamento 
marxista, embora minoritários e frequentemente disputados, persistem no interior da escola. Partidos políticos, movimentos sociais de diferentes tendências socialistas e marxistas utilizam da auto-educação para politizar e construir, junto às classes dominadas, formas de luta política, de compreensão e interpretação dos processos políticos e econômicos. Por sua vez, a denúncia freqüente da natureza de classe dos conteúdos e das práticas escolares, a explicitação dos conflitos funcionais, ou ainda quando se procura expandir os conhecimentos científicos objetivos às classes trabalhadoras, constituem certamente formas de luta interna à escola. Contudo, enquanto função escolar, a transmissão de conteúdos socialmente produzidos, ainda que de uma perspectiva histórica e dialética, é insuficiente para mudar a natureza de classe da escola. Neste sentido, o tipo de contradição e de negação possível no interior da escola seria o de acirrar as contradições secundárias, os conflitos funcionais .

Qualquer transformação interna à escola no sentido de torná-la, de fato, uma escola a serviço das classes trabalhadoras exigiria o rompimento com o compromisso orgânico do aparelho educacional com a reprodução da divisão capitalista do trabalho - esta sim uma contradição principal no interior do modo de produção capitalista. As reivindicações expressas pelo movimento socialista - união entre trabalho produtivo e ensino, preparação dos alunos simultaneamente para o exercício do trabalho de concepção e de trabalho de execução (técnica e ciência ou politecnia), resgate das experiências concretas de vida e de trabalho, permitindo que, desde cedo, os filhos dos trabalhadores possam compreender o processo de produção e de reprodução da vida social - não podem se realizar, não obstante, na vigência do aparelho estatal burguês, nem das relações de produção capitalistas. Neste sentido, a ruptura com a divisão capitalista do trabalho implicaria, necessariamente, na revolução social.

Finalizo estes apontamentos com uma indagação: embora algumas críticas às armadilhas das leituras não-economicistas sejam pertinentes, a rejeição das análises desenvolvidas pela "sociológica crítica da educação" no campo educacional não pode nos colocar em outras tantas e mais perversas armadilhas, como as do idealismo e do reformismo?

\section{Referências}

ALVES, G. L. A produção da escola pública contemporânea. Campo Grande: Editora da UFMS; Campinas: Autores Associados, 2001.

BAUDELOT, C.; ESTABLET, R. La escuela capitaslita. México: Siglo Veintiuno, 1975.

ESTABLET, R. A escola: as instituições e os discursos. Revista Tempo Brasileiro, Rio de Janeiro, n. 35, p. 93 125, out./dez. 1973.

LINDENBERG, D. L'Internationale communiste et l'ecole de classe. Paris: François Maspero, 1972.

MARX, K. Para crítica da economia política. São Paulo: Abril Cultural, 1982.

PONCE, A. Educação e luta de classes. São Paulo: Cortez, 1990.

PORTUGAL, A. Marxismo e educação: marxismo e reformismo na produção do conhecimento em educação hoje. Revista de Educação - PUC, Campinas, n. 23, p. 9-19, nov. 2007.+

SAES, D. Marxismo e história. Revista Crítica Marxista, São Paulo, n. 1, p. 39-59, 1994.

SILVA, T. T. O que produz e o que reprodu乏, em educação: ensaios de sociologia da educação. Porto Alegre: 
Artes Médicas, 1992.

SAVIANI, D. Escola e democracia. São Paulo: Autores Associados; Cortez, 1987. (Coleção Polêmicas do nosso tempo, n. 5).

TURCHETTO, M. As características específicas da transição ao comunismo. In: NAVES: M. B. (Org.). Análise marxista e sociedade de transição. Campinas: IFCH/Universidade Estadual de Campinas, 2005.

(Coleção Idéias, n. 5).

WOOD, E. Democracia contra capitalismo. São Paulo: Boitempo, 2003.

\section{Notas}

${ }^{1}$ Graduada em Pedagogia pela Universidade Estadual de Campinas (1988), Mestre em Ciência Política pela Universidade Estadual de Campinas (1994). Doutora em Ciências Sociais pela Universidade Estadual de Campinas (2004). Atualmente é professora junto ao Departamento de Ciências Sociais da Universidade Federal de Uberlândia (2009). Email: tropia@uol.com.br 